IMAGES IN CLINICAL MEDICINE

Lindsey R. Baden, M.D., Editor

\title{
Congenital Duodenal Obstruction and Double-Bubble Sign
}

Jorge Correia-Pinto, M.D., Ph.D. Andreia Ribeiro, M.D.

University of Minho

Braga, Portugal

jcp@ecsaude.uminho.pt

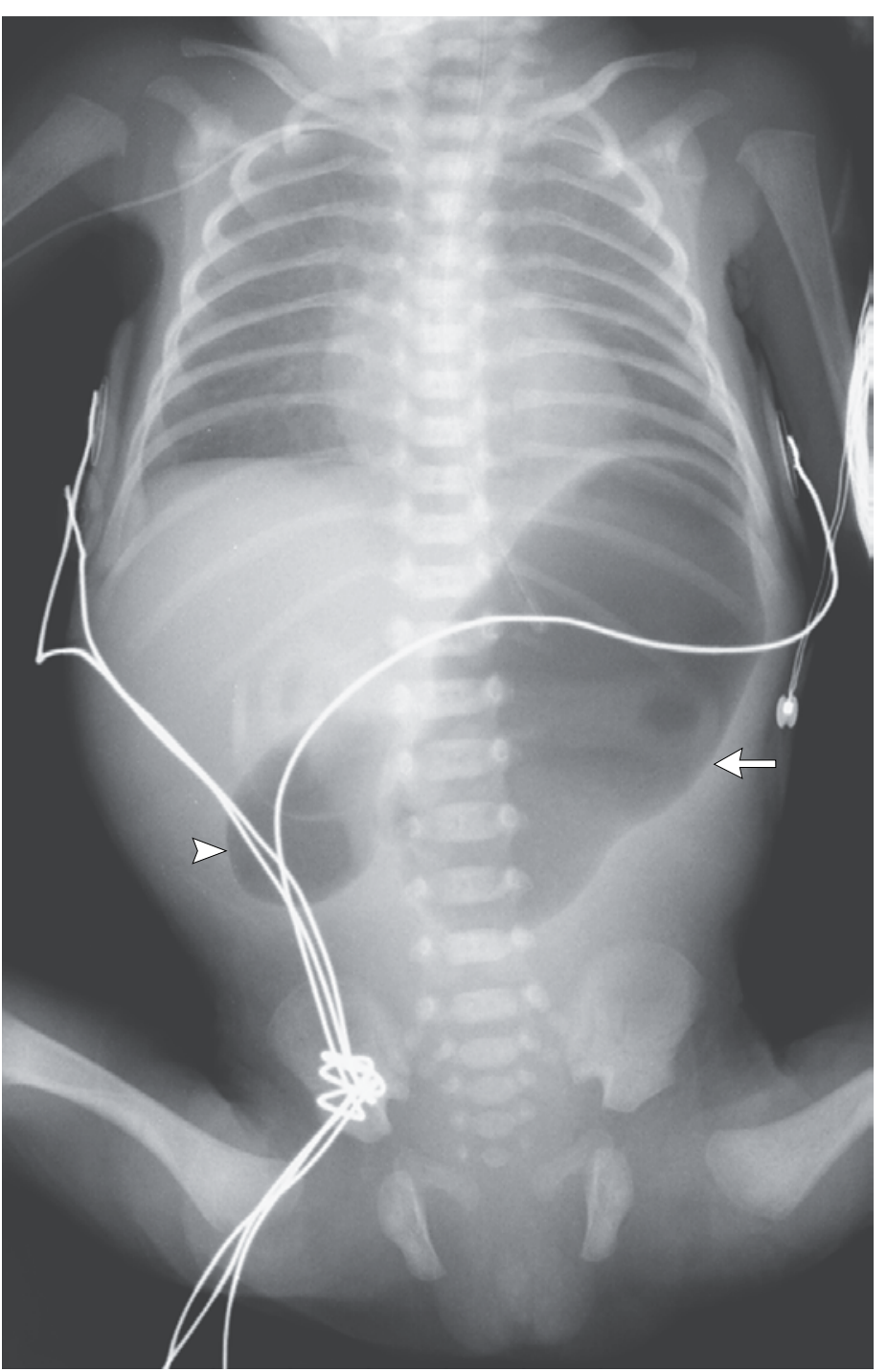

GIRL WEIGHING $1080 \mathrm{G}$ WAS BORN AT A GESTATIONAL AGE OF 29 WEEKS BECAUSE OF SPONTANEOUS PREMAture rupture of membranes. Enteral feeding through a nasogastric tube was started 8 hours after birth but was not tolerated. The infant's condition deteriorated, with ongoing episodes of nonbilious vomiting and a lack of stools since birth. The physical examination showed mild upper abdominal distention, with apparent discomfort on abdominal palpation. Abdominal radiography showed the double-bubble sign — a distended stomach (arrow) and proximal duodenum (arrowhead) - which is pathognomonic of congenital duodenal obstruction. There was no air distal to the level of obstruction in the D2 segment of the duodenum. Laparoscopy showed duodenal atresia type 1, which was repaired with a diamond-shaped duodenal anastomosis. Oral feedings were initiated successfully on the seventh postoperative day. The postoperative period was uneventful. 